\title{
Social Skills: Adolf Meyer's Revision of Clinical Skill for the New Psychiatry of the Twentieth Century
}

\author{
SUSAN LAMB* \\ Department of History and Classical Studies, McGill University, Montreal, Canada
}

\begin{abstract}
Adolf Meyer (1866-1950) exercised considerable influence over the development of Anglo-American psychiatry during the first half of the twentieth century. The concepts and techniques he implemented at his prominent Phipps Psychiatric Clinic at Johns Hopkins remain important to psychiatric practice and neuro-scientific research today. In the 1890s, Meyer revised scientific medicine's traditional notion of clinical skill to serve what he called the 'New Psychiatry', a clinical discipline that embodied social and scientific ideals shared with other 'new' progressive reform movements in the United States. This revision conformed to his concept of psychobiology - his biological theory of mind and mental disorders - and accorded with his definition of scientific medicine as a unity of clinical-pathological methods and therapeutics. Combining insights from evolutionary biology, neuron theory and American pragmatist philosophy, Meyer concluded that subjective experience and social behaviour were functions of human biology. In addition to the time-honoured techniques devised to exploit the material data of the diseased body - observing and recording in the clinic, dissecting in the morgue and conducting histological experiments in the laboratory - he insisted that psychiatrists must also be skilled at wielding social interaction and interpersonal relationships as investigative and therapeutic tools in order to conceptualise, collect, analyse and apply the ephemeral data of 'social adaptation'. An examination of his clinical practices and teaching at Johns Hopkins between 1913 and 1917 shows how particular historical and intellectual contexts shaped Meyer's conceptualisation of social behaviour as a biological function and, subsequently, his new vision of clinical skill for twentieth-century psychiatry.
\end{abstract}

Keywords: Meyer, Adolf, Psychiatry, History, Progressive Era, Psychobiology

\footnotetext{
* Present address: Department of History and Classical Studies, McGill University, LEA 609, 855 Sherbrooke St W., Montreal, QC, H3A 2T7, Canada. Email address for correspondence: susanlamb444@ gmail.com This research was supported by the Social Sciences and Humanities Research Council of Canada (Award \#7562013-0291). I thank Delia Gavrus, Nick Whitfield, Steve Sturdy and the anonymous reviewers for their valuable comments on earlier drafts of this article.
} 


\section{Introduction}

'Psychiatry deals with the social organ of man', Adolf Meyer declared confidently in 1913 to his medical peers at the International Congress of Medicine in London. ${ }^{1}$ In the audience sat fellow physicians and researchers with a special interest in abnormal mental states and their causes. Many of his listeners were eager to hear Meyer's report as director of a new psychiatric clinic at Johns Hopkins University in the United States. The Henry Phipps Psychiatric Clinic had opened a few months earlier to become that country's first academic institute devoted to research and training in psychiatry. ${ }^{2}$ Meyer described his wellappointed clinic in Baltimore with beds for eighty-eight patients, laboratories for histology and experimental psychology, and classrooms for clinical demonstrations and instruction in brain anatomy and development. Modern facilities also supported comprehensive neurological and psychological assessments of patients, including continuous observation, and a daily regimen that combined physical, occupational and talk therapies. Built according to Meyer's general specifications, the clinic differed from the large custodial state institutions where he had worked as pathologist and teacher for sixteen years before his headline-making appointment to Johns Hopkins in 1908. He staffed and organised the Phipps Clinic to facilitate a clinical science of psychiatry that operated like the other medical disciplines at the famous research university - producing scientific knowledge and well-trained specialists. Meyer emphasised to Congress attendees, however, that clinical psychiatry in the twentieth century must address an aspect of human biology that other medical sciences could disregard. 'Internal medicine cultivates the pathology and therapy of special organs', he explained. 'Psychiatry has to add to this the study of the broader integrations, not only of individual organs, but also of the person as a whole in a system of social adaptation'. ${ }^{3}$ For Meyer, that meant mobilising programmes of scientific research, advanced training and therapeutics derived not only from the material data of the sick or autopsied body, but also the ephemeral data of social dysfunction.

Adolf Meyer (1866-1950) possessed tremendous authority within Anglo-American psychiatry throughout the first half the twentieth century. He was a Swiss émigré with an elite German medical education and advanced training with some of Europe's most accomplished brain researchers. He had a predilection for British evolutionary biology and American pragmatist philosophy, and a lifelong aversion to reductionistic explanations of normal psychology or psychiatric disorders - be they material, psychical, sexual or behavioural. Based on his reputation for introducing scientific methods into outdated American mental asylums, in 1908 he was appointed first Chief of Psychiatry at Johns Hopkins, at that time widely acknowledged as the pre-eminent medical school and research university in the United States. The position placed him on par with other prominent Johns Hopkins chiefs such as William Osler and William Welch, both of whom had campaigned

\footnotetext{
${ }^{1}$ Adolf Meyer, 'The psychiatric clinic, its aims (educational and therapeutic), and the results obtained in respect to promotion of recovery (1913)', in E.E. Winters (ed.), The Collected Papers of Adolf Meyer, vol. 2 (Baltimore: Johns Hopkins University Press, 1951), 203. Originally published in Transactions of the 17th International Congress of Medicine in London, Section 12, Part 2 (1913), 9-11.

2 There were state-run facilities established earlier that successfully emulated the authoritative institutes of Europe's medical universities, for example the New York Pathological Institute and psychopathic hospitals in Boston, MA and Ann Arbor, MI.

3 Adolf Meyer, 'The aims of a psychiatric clinic' (1913), in Collected Papers vol. 2, op. cit. (note 1), 200. Originally published in Transactions of the 17th International Congress of Medicine in London, Section 12, Part 1 (1913), 1-11.
} 
for a psychiatric clinic at Johns Hopkins and for Meyer's appointment. ${ }^{4}$ Opened in 1913, the clinic quickly became a leading centre for advanced training in psychiatry and, until his retirement in 1941, this powerful institutional position assured Meyer a leadership role within the discipline. In a period of rapid growth for psychiatry in the 1930s and 1940s, his adherents occupied leadership positions within the young and impressionable discipline. They disseminated his concepts and methods to academic centres in the United States, Canada and Britain, where multiple generations of clinicians were taught to employ the Meyerian approach to study and treat mental disorders. Meyer utilised his influence to shape psychiatry's accepted practices and training procedures according to his own distinctive revision of longstanding notions of clinical skill in medical research, teaching and practice. ${ }^{5}$

In the 1890s, Meyer revised scientific medicine's traditional definition of clinical skill to serve what he called the 'new psychiatry', a clinical discipline based on the principles of biological adaptation, and that shared social ideals with other 'new' progressive reform movements in the United States. ${ }^{6}$ This revision conformed to his biological theory of mind and mental illness, which he called 'psychobiology', and accorded with his definition of scientific medicine as the unification of 'pathology and therapy'. ${ }^{7}$ Combining insights derived from evolutionary biology, the new neuron theory and American pragmatist philosophy, Meyer concluded that subjective experience and social behaviour were functions of human biology - causal agents, not inert side-effects, in the human organism's interaction with its environment. For him, it followed that some pathological processes underlying mental disorders developed not organically, at the level of tissues or cells, but functionally in experiences and social interactions. Accordingly, he redefined what clinical skill ought to mean for psychiatry: it could no longer be based solely on correlating patients' symptoms with evidence of disease, but must also comprise techniques and aptitudes for discerning causal relationships between social dysfunction and pathological experiences. In addition to the time-honoured techniques devised to exploit the material data of the diseased body - observing and recording in the clinic, dissecting in the morgue and conducting histological experiments in the laboratory - Meyer insisted that the new clinical psychiatrist also be skilled in recognising and exploiting the productive nature of interpersonal relationships in order to conceptualise, collect, analyse and apply the ephemeral data of 'social adaptation'. For this analysis, I rely on a prescriptive manual called Outlines of Examinations published by Meyer in 1918, on his scientific papers and

\footnotetext{
${ }^{4}$ William Osler to Henry Phipps, 8 July 1908, CUS417/114.135, Harvey Cushing Fonds (P417), Osler Library Archive Collections, Osler Library of the History of Medicine, McGill University, Montreal, Canada; William Welch to Henry Hurd, 12 June 1908, I/3988/I, Adolf Meyer Collection, Alan Chesney Medical Archives, Johns Hopkins Medical Institutions, Baltimore, Maryland, USA (hereafter AMC).

5 See Michael Gelder, 'Adolf Meyer and his Influence on British Psychiatry', History of Psychiatry, 14 (2003), 475-508; Gerald Grob, 'Adolf Meyer on American Psychiatry in 1895', American Journal of Psychiatry, 119 (1963), 1135-42; David Paul Lumsden, 'Professional Godfather: The Role of Adolf Meyer and his Students in Canadian and Chinese Psychiatry', Santé Culture/Culture Health, 9 (1992/3), 226-59.

${ }^{6}$ Adolf Meyer, 'Review of Recent Text-books of Anatomy and Pathology of the Nervous System', Journal of Comparative Neurology, 11 (1901), xliii. Barbara Sicherman also links Meyer to a 'new' American psychiatry that emphasised behavioural and psychoanalytic models. See Barbara Sicherman, 'The new psychiatry: medical and behavioral science, 1895-1921', in Jacques Quen and Eric Carlson (eds), American Psychoanalysis: Origins and Development (New York: Brunzer-Mazel, 1978), 20-37.

${ }^{7}$ Adolf Meyer, 'A few remarks concerning the organisation of the medical work in large hospitals for the insane' (1902), in Collected Papers vol. 2, op. cit. (note 1), 89-90. Originally printed privately, 1902. See also Adolf Meyer, 'Considerations on psychiatry' (1940), in E.E. Winters (ed.), The Collected Papers of Adolf Meyer vol. 3 (Baltimore: Johns Hopkins University Press, 1951), 461.
} 
private correspondence, and on examples drawn from medical records of patients admitted to the Phipps Clinic. I examine his clinical practices and teaching at Johns Hopkins between 1913 and 1917 to illuminate the relationship between Meyer's conceptualisation of social behaviour as a biological function and his new vision of clinical skill for twentieth-century psychiatry.

Elucidating Adolf Meyer's conception of clinical skill helps to reconcile an apparent paradox within current scholarship on the Meyerian project that so influenced American psychiatry. Scholarly consensus forms around his singular and lasting impact on the discipline. ${ }^{8}$ Yet many historians suggest that 'psychobiology' was merely a form of eclecticism that had little bearing on his success as psychiatry's foremost professionaliser.' Other historians have gone further to say that his pronouncements about psychobiology were devoid of substance and his research methods arbitrary. ${ }^{10}$ Jack Pressman, on the other hand, concludes that Meyer's psychobiological model became the master paradigm of American psychiatry after World War I precisely because of its multidisciplinary character, thereby consolidating authority in a new medical specialist - the psychiatrist - who became responsible for all mental abnormalities, from acute psychosis to depression to chronic worry. ${ }^{11}$ Building on Pressman's insights, I argue elsewhere that the premise of psychobiology was that an action of the body's nervous apparatus (at once anatomical and physiological) and its functional expression (as mental activity and social behaviour) constituted a single adaptive response of the human organism. This allowed Meyer to advertise psychobiology as an interpretive framework that integrated data and methodologies belonging to fundamentally different phenomena (anatomical, physiological and experiential). My analyses of investigative and therapeutic practices he instituted at the Phipps Clinic, and of his interactions with Phipps patients and staff, showed how Meyer's selective use of techniques derived from clinical medicine, neurology, pathology, histology, natural history, experimental psychology, moral therapy and psychoanalysis were united by the principles of psychobiology to serve what he considered a single, scientific enterprise: a clinical science of psychiatry. ${ }^{12}$ Here, I identify his conceptualisation of 'social adaptation' as a biological function with the new set of clinical skills he taught at Johns Hopkins, and which he effectively implemented as a disciplinary standard for American psychiatry. This analysis offers evidence, I suggest,

\footnotetext{
${ }^{8}$ Gerald Grob, Mental Illness and American Society 1875-1940 (Princeton: Princeton University Press, 1983), 112; Nathan Hale, Freud and the Americans: The Beginnings of Psychoanalysis in the United States 18761917 (Oxford: Oxford University Press, 1990), 157; Ruth Leys, 'Adolf Meyer: a biographical note', in R. Leys and R.B. Evans (eds), Defining American Psychology: The Correspondence Between Adolf Meyer and Edward Bradford Titchener (Baltimore: Johns Hopkins University Press, 1990), 54; Richard Noll, American Madness: The Rise and Fall of Dementia Praecox (Cambridge, MA: Harvard University Press, 2011), 36; Jack Pressman, Last Resort: Psychosurgery and the Limits of Medicine (Cambridge: Cambridge University Press, 1998), 431; Andrew Scull, Madhouse: A Tragic Tale of Megalomania and Modern Medicine (New Haven: Yale University Press, 2005), 161; Edward Shorter, A History of Psychiatry: From the Era of the Asylum to the Age of Prozac (New York: John Wiley, 1997), 101.

${ }^{9}$ Grob, Mental Illness, op. cit. (note 8), 113-43 and 236-87; Shorter, op. cit. (note 8), 111; Andrew Abbott, The System of Professions: An Essay on the Division of Expert Labor (Chicago: University of Chicago Press, 1988), 52.

${ }^{10}$ Scull, op. cit. (note 8), 239; Noll, op. cit. (note 8), 159; S. Nassir Ghaemi, 'Adolf Meyer: Psychiatric Anarchist', Philosophy, Psychiatry, and Psychology 14 (2007), 343.

${ }^{11}$ Pressman, Last Resort, op. cit. (note 8), 18-46; Jack Pressman, 'Review Essay: Psychiatry and its Origins', Bulletin of the History of Medicine 71/1 (1997), 139.

12 S.D. Lamb, Pathologist of the Mind: Adolf Meyer and the Origins of American Psychiatry (Baltimore: Johns Hopkins University Press, 2014).
} 
that - far from being incidental - the theoretical principles of psychobiology were at the core of Meyer's professional leadership and influence.

\section{Contextualising Meyerian Psychiatry and the Phipps Clinic}

Meyer's new definition of clinical skill in psychiatry reflected his efforts in the years before World War I to apply scientific methods already validated by physicians during the previous century to emergent biological conceptions of mental illness as maladaptation. Most medical practitioners and investigators conceptualised disease as a material entity that existed apart from the body it devastated, attributable to a distinctive anatomical lesion, micro-organism or chemical reaction. This ontological view is often labelled the 'disease model', within which scientific medicine's primary objective was to locate disease in the sick or autopsied body. Its origins in early nineteenth-century Paris, and its significance to the development of medical science and specialisation, are both important for understanding the relationship between Meyer's theory of psychobiology and his conviction that the skilled psychiatrist employed traditional methods of scientific medicine yet dispensed with old assumptions about the materiality of all pathology.

In post-Revolutionary Paris, the secularisation of the city's massive Catholic hospitals provided elite physicians with unrestricted access to patients' bodies before and after death. Systematically, they examined living patients and, when they died, they performed autopsies on those same bodies. No longer a Christian hospice, the crowded ward was now a source of research material and renamed la clinique after the Greek word for sickbed. In a dedicated dossier for each patient, these new 'clinicians' meticulously documented their observations at the bedside and pathological lesions in organic tissues discovered during autopsy. Using comparative and statistical methods to study thousands of recorded cases, they were able to discern otherwise imperceptible patterns of pathology. The 'clinicalpathological method' elucidated for the first time the relatively predictable courses of several common diseases. It placed diseased organs and their tissues at the centre of medical discovery, and established record keeping, clinical observation and dissection as essential techniques of investigation. The new term clinician signified the hospital physician who used this novel method to derive knowledge about disease - continually collecting and correlating data from both living and dead bodies. ${ }^{13}$

The clinical-pathological method endured as a guiding principle of scientific medicine throughout the nineteenth century. Pathology, the study of disease and diagnosis, emerged as a distinct discipline. Well-funded German universities opened institutes devoted to specialised research, which became citadels of scientific work and advanced training in medicine. Improvements to the microscope enabled investigators to study disease at the cellular level, fostering new laboratory disciplines such as bacteriology, histology and neuro-pathology. In the 1880s, experimentalists across Europe affirmed the principles of germ theory and produced life-saving vaccines. By century's end, the material basis of all sickness - whether at the anatomical or cellular level - appeared self-evident. Techniques of clinical record keeping grew more significant. Nineteenth-century clinicians developed the standardised 'case history' that merged myriad data of clinical signs and pathological

13 Russell C. Maulits, Morbid Appearances: The Anatomy of Pathology in the Early Nineteenth Century (Cambridge: Cambridge University Press, 1987/2002), 9-19. 
processes into a single narrative of disease. ${ }^{14}$ Meyer's elite training under prominent German, French and British clinicians between 1887 and 1892 was rooted in this model of scientific medicine. At no time did it occur to him that the New Psychiatry would proceed according to any other than this established methodology.

German scientific institutes devoted to psychiatry emerged in the 1870 s with roots in traditional mental asylums and hospital wards for neurological diseases. In general, the term 'psychiatry' in this period was associated with the study of abnormal mental states (or psychopathology) in living patients, and the term 'neurology' with studying the normal mechanics and diseases of the nervous system. At institutes devoted to clinicalpathological research, these enterprises tended to merge. In the 1880s, for example, clinicians in Vienna confirmed correlations between symptoms of aphasia, an impairment involving speaking and writing, and lesions discovered in a particular area of autopsied brains. These concrete but limited findings inspired widespread confidence that a unique histological basis would be identified for every distinct form of psychopathology. ${ }^{15}$

When Meyer arrived in the United States in 1892, however, no such lesion had materialised. Not for another decade would investigators identify the spirochete responsible for neuro-syphilis. ${ }^{16}$ Theoretical and methodological discord characterised the overlapping and ill-defined specialties of neurology and psychiatry in Europe and North America. Experiments by clinicians such as August Forel, Meyer's doctoral advisor, had confirmed distinctive and autonomous nerve cells termed neurons, sparking the controversial suggestion that the nervous system was not a connective network of nerves. New work in evolutionary biology, particularly that of Charles Darwin, and the experimental results of physiologists such as Claude Bernard, also challenged notions of a strictly anatomical basis of mental illness. ${ }^{17}$ Investigators began to study other possible etiological factors including metabolism, infection and 'subconscious' mental processes. In the United States, psychologists such as William James and John Dewey developed 'pragmatic' epistemologies based on biological development as alternatives to deterministic explanations based on the reflex arc. They viewed the interaction between individual and environment as a dynamic, not determined, exchange - a premise Meyer thought was supported by the emerging science of neurons. ${ }^{18}$ By 1898 , he was determined to transform American psychiatry into a branch of biology focused on the dynamic interaction between a maladjusted person and his or her environment. His challenge was how to study maladjustment using established clinical-pathological methods devised for studying the diseased body.

In the United States, Meyer found no academic discipline devoted to psychiatry and very few neurologists conducting clinical-pathological research; most neurologists were private practitioners dealing with an epidemic of 'nervousness' associated with the diagnosis of neurasthenia. He also discovered that the country's many mental asylums had not participated in the transformation that had made the university hospital an essential

\footnotetext{
${ }^{14}$ Steve Sturdy, 'Scientific Method for Medical Practitioners: The Case Method of Teaching Pathology in Early Twentieth-Century Edinburgh', Bulletin of the History of Medicine, 81 (2007), 760-92.

${ }^{15}$ Eric J. Engstrom, Clinical Psychiatry in Imperial Germany: A History of Psychiatric Practice (Ithaca, NY: Cornell University Press, 2003), 88-120.

16 John Parascandola, Sex, Sin, and Science: A History of Syphilis in America (Westport, CT: Praeger, 2008), $18-22$.

${ }^{17}$ Lamb, Pathologist, op. cit. (note 12), 65-6.

${ }^{18}$ Ibid., 79.
} 
part of medical inquiry and teaching. ${ }^{19}$ A legal declaration of insanity was typically a prerequisite for admission, and most asylums were crowded with cases popularly perceived as hopeless. Reports of mistreatment and false confinement, as well as the common belief that insanity was inherited and incurable, tainted public perceptions of asylums and the doctors inside them. For most Americans in this period, a mental hospital - like those in which Meyer worked before his move to Johns Hopkins - was a terrifying place of last resort. ${ }^{20}$

When the Phipps Clinic opened in 1913 it publicised a psychiatric reform movement already underway in the United States. A small group of elite specialists, within which Meyer was a leading figure, tried to transcend the cynicism fostered by the deterioration of mental asylums by abandoning the absolute distinction between health and disease, sanity and insanity. They embraced new explanations based on biological adaptation and maladjustment. ${ }^{21}$ This conceptual shift - from incurable insanity to potentially treatable maladjustment - resonated with the progressivism and environmentalism that had emerged as governing views in the United States, both of which posed serious challenges to pessimistic inferences of social and hereditary determinism. ${ }^{22}$ Meyer linked his psychobiological psychiatry to other progressive reform movements, especially those spearheaded by his close associates Jane Addams at Hull House and John Dewey through pragmatism and the New Psychology. ${ }^{23}$ He spoke confidently about studying and treating severe mental disturbances and so-called nervousness at the new Phipps Clinic. Such optimism dovetailed with Americans' increasing fascination with self-improvement and spiritual 'mind-cures'. ${ }^{24}$ The clinic's association to Johns Hopkins advertised its scientific credibility to physicians and their patients, and Meyer used his authoritative position to reshape negative attitudes about psychiatric illnesses and institutions, and to influence the trajectory of American psychiatry. ${ }^{25}$

During its first five years of operation, 1913-17, the clinic attracted and admitted a socially diverse group of 1772 patients with a wide range of symptoms and motivations for using the new psychiatric hospital. The vast majority of admissions were voluntary, the average being fifty-six days and the longest that of a 39-year-old taxi driver from Maryland hospitalised for 1015 days. Men and women were admitted in roughly even numbers and occupied separate wings of the five-story clinic, each made up of communal wards with some private rooms. ${ }^{26}$ As did its parent institution, the clinic could waive or subsidise hospital fees for local poor and working-class patients by catering to those willing to pay

${ }^{19}$ Charles Rosenberg, The Care of Strangers: The Rise of America's Hospital System (Baltimore: The Johns Hopkins University Press, 1987).

${ }^{20}$ Grob, Mental Illness, op. cit. (note 8), 7-29; Gerald Grob, The Inner World of American Psychiatry 1890-1940 (New Brunswick, NJ: Rutgers University Press, 1985), 1-18.

${ }^{21}$ Gerald Grob, The Mad Among Us: A History of the Care of America's Mentally Ill (Cambridge, MA: Harvard University Press, 1994), 142; Pressman, 'Psychiatry and its Origins', op. cit. (note 11), 137-8.

22 John C. Burnham, 'Psychiatry, Psychology and the Progressive Movement', American Quarterly, 12/4 (1960), 457-65.

23 John C. Burnham, Psychoanalysis and American Medicine, 1894-1918 (New York: International Universities Press, 1967), 55; Lamb, Pathologist, op. cit. (note 12), 14-16; Daniel Rodgers, 'In Search of Progressivism', Reviews in American History, 10 (1982), 113-32.

${ }^{24}$ Hale, op. cit. (note 8), 71-173; Eva Moskowitz, In Therapy We Trust: America's Obsession with Self Fulfillment, (Baltimore: The Johns Hopkins Press, 2001), 19-29: 41-4

25 Draft of letter, Meyer to William Welch, n.d. (c. June 1908), I/3988/1, AMC, op. cit. (note 4).

${ }^{26}$ For detailed analyses, see Susan Lamb, 'Social, Motivational, and Symptomatic Diversity: Analysis of the Patient Population of the Phipps Psychiatric Clinic, 1913-17', Canadian Bulletin for Medical History, 29 (2012), 243-63. 
higher fees for private accommodations and consultations with the university's eminent clinicians. ${ }^{27}$ Meyer expected his unusually large staff of psychiatrists, attendants and trained nurses and occupational therapists to convince every patient - including the very wealthy and the very sick - to participate in communal meals, occupations and social activities, hydrotherapy and psychotherapy. His clinical staff and trainees utilised state-of-the-art laboratory facilities for work in chemistry, histology, neuropathology and experimental psychology. They also attended clinical lectures in which Phipps patients served as teaching material. Meyer and his senior staff of four psychiatrists directed all clinical and therapeutic activities, and Meyer hired and supervised scientists to oversee the laboratories and pursue original research. ${ }^{28}$ Like a general hospital, all admissions were at the discretion of physicians, who were not obliged to accept individuals in the custody of state authorities. Meyer based admission and discharge decisions on his evaluation of each case's usefulness to clinical work or teaching, and his perception of the patient's capacity for collaboration. Each and every patient, he was convinced, was a remarkable source of data for the New Psychiatry.

\section{Conceptualising the Data of Social Adaptation}

Meyer conceptualised the data of what he called 'social adaptation' in terms of his theory of psychobiology, first formulated in 1898. Psychobiology combined the new theory of autonomous neurons, John Hughlings Jackson's evolutionary model of a hierarchical nervous system, and the epistemology of American pragmatist philosophy. The fundamental premise of psychobiology was that an action of the body's nervous apparatus and its expression as mental activity constituted a single adaptive response of the human organism. Meyer called this adjustment a 'psychobiological reaction' and made it a critical unit of analysis for psychiatrists. He described the brain as the 'mechanism of sensory-motor plasticity', a responsive, not fixed, anatomical and physiological apparatus. ${ }^{29}$ Neural activity was expressed functionally as the mind, which he identified as the 'mechanism of adaptation and behavior'. ${ }^{30}$ According to Meyer, the result of this biological integration was the 'person', an irreducible unit. A person adjusted constantly not only to his or her physical surroundings, but also to a complex environment of symbolic stimuli and tacit social codes - what he called 'social adaptation'. He reasoned that through an endless series of psychobiological reactions, a biological function called mentation integrated and regulated a complex suite of adaptive resources accumulated during human evolution, including physiological systems, instinctual urges, emotional responses, learning, memory, perception of reality, imagination, abstract reasoning, social co-operation and altruism. Meyer's model of psychobiology framed mental disorders

\footnotetext{
${ }^{27}$ Unlike Johns Hopkins Hospital, the Phipps Clinic did not admit so-called 'coloured' patients, the reasons for which have yet to come to light.

${ }^{28}$ At the Phipps, John Watson conducted experiments on which he based behaviourism, an approach that was irreconcilable with his mentor's anti-reductionist psychobiology. Meyer replaced Watson with Curt Richter, notable for his findings on circadian rhythms in animal behaviour among other significant scientific contributions. See Ruth Leys, 'Meyer, Watson, and the Dangers of Behaviorism', Journal of the History of the Behavioral Sciences, 20 (1984), 128-49; Jay Schulkin, Curt Richter: A Life in the Laboratory (Baltimore: The Johns Hopkins Press, 2005).

${ }^{29}$ Adolf Meyer, 'Anatomical Facts and Clinical Varieties of Traumatic Insanity', American Journal of Insanity, 60 (1904), 373.

${ }^{30}$ Adolf Meyer, 'The Aims of a Psychiatric Clinic', Proceedings of the Mental Hygiene Conference, New York, 1912 (New York: Committee on Mental Hygiene, 1912), 119.
} 
not as distinct diseases, as did the majority of his peers in this era, but as types of maladjustment. He deemed a patient's psychobiological reactions to his or her environment - manifest in thoughts and behaviour - to be observable natural phenomena, subject to scientific inquiry and a promising site of medical intervention. ${ }^{31}$

Meyer's greatest obstacle to establishing psychobiology as the basis of psychiatry was the strong orientation toward material reductionism in medical science. He needed to assimilate the ephemeral data of psychobiological reactions, or social adaptation, into the clinical-pathological method premised on the disease model. In 1899, he lamented that medicine remained on a 'pre-biological, materialistic standpoint' ${ }^{32}$ In 1908, the year he was appointed to Johns Hopkins, Meyer declared that psychobiology would liberate psychiatry from the 'narrowing straight-jacket of traditional assumptions' that had convinced many of his medical peers that any scientific approach to mental illnesses involved correlating clinical observations with pathological processes taking place inside the body. He was convinced that subjective experience and social functioning were also sites of pathological processes. ${ }^{33}$

To validate the ephemeral data of social adaptation, he turned to American pragmatism for epistemological support. He appropriated William James's radical empiricism and, in particular, James's instrumentalist revision of the philosophical principle of 'common sense'. James argued that the value of any voluntary act was dependent upon its usefulness to the situation in which it emerged and was applied; it was considered useful or 'true' if it effectively attained the individual's desired end. Knowledge and truth were not universal but always dependent upon a specific interpretive context, he asserted, and human experience was progressive and ever-expanding. According to James, the Scottish philosophy of common sense reflected this instrumental character of all knowledge. He argued, however, that (like truth) common sense was not universal since it had evolved according to its use by individuals with subjective goals and beliefs. James redefined common sense as effective judgment - always relative to a specific context, and always formulated according to an individual's accumulated experience. ${ }^{34}$

Adopting this instrumentalist view of common sense, Meyer concluded that subjective experience and social behaviours were integral biological functions in a person's total adaptive performance. Each person adjusted to a uniquely constituted environment comprising two spheres: perceptions of external reality (shared with others) and the happenings of his or her internal mental life. Both objective reality and subjective experience were dominated by symbols and social conventions that required interpretation using common sense. Meyer argued that abnormal thinking or social dysfunction,

\footnotetext{
${ }^{31}$ Lamb, Pathologist, op. cit. (note 12), 66-85. Meyer's original formulation of psychobiology appeared in 1898, embedded in the pages of a lengthy literature review published in two parts: Adolf Meyer, 'Critical Review of the Data and General Methods and Deductions of Modern Neurology: Part 1', Journal of Comparative Neurology, 8 (1898), 113-47 and Adolf Meyer, 'Critical Review of the Data and General Methods and Deductions of Modern Neurology: Part 2', Journal of Comparative Neurology, 8 (1898), 249-313.

32 Adolf Meyer, 'Psychopathology' (1899), in Collected Papers vol. 2, op. cit. (note 1), 283. Originally published in Clark University, 1889-99: Decennial Celebration Volume, 1899.

33 Adolf Meyer, 'The Problems of Mental Reaction-Types, Mental Causes and Diseases', Psychological Bulletin, 5 (1908), 254-5.

${ }^{34}$ William James, 'A world of pure experience' (1904), in J.M. Capps and D. Capps (eds), James and Dewey on Belief and Experience (Chicago: University of Chicago Press, 2005), 144-61; Charlene Haddock Seigfried, 'The Philosopher's 'License': William James and Common Sense', Transactions of the Peirce Society, 9 (1983), 273-90.
} 
therefore, was as legitimate and productive a source of pathological material as a brain lesion or syphilitic spirochete..$^{35}$

To assimilate this indispensable new source of data into the traditional clinicalpathological method, clinicians required a standard of normal against which to identify pathologies. James's concept of common sense as an instrument of individual adaptation served this function in Meyerian psychiatry. Meyer advertised common sense as the sensory modality that served mentation, supplying knowledge of those stimuli requiring evaluation according to experience. He defined mental health as a natural state of psychobiological balance between lower primal functions and higher abilities such as cognition, abstract thought, delayed gratification, imagination and empathic reasoning. Mentation regulated a person's psychobiological reactions to assure appropriately differentiated responses to imminent danger, for example, and merely an abstract idea of being in danger. 'When it comes to the mechanism of behavior itself, to what we call our mind', he explained in 1912, 'we find that behavior is regulated by feelings, by fears and desires, by knowledge and wisdom, by personal desire or social custom'. ${ }^{36}$ Common sense circumscribed deeply internalised cultural norms that influenced the workability of myriad psychobiological adjustments involving the co-ordination of physiological, instinctual, emotional, intellectual and social responses. Many of these adjustments became habitual, performed without conscious awareness. Wearing clothes, using money or withholding urination until socially acceptable, are good examples of what Meyer considered normal and, more importantly, useful psychobiological habits formed in accordance with common sense. He proposed that psychiatrists could be trained to employ this principle critically in the clinic. 'Our comparative measure of the various disabilities', he wrote in 1908, 'is the normal complete reaction'. ${ }^{37}$ A psychiatrist had to learn to differentiate 'efficient' from 'inefficient' reactions by employing social interaction and his or her own critical common sense.

During his own medical training, Meyer learned that the clinician's task was to scrutinise all data in the case history, to identify what aspects of the case were clinically salient and to mobilise the appropriate techniques to elucidate those factors. Part of this process was to differentiate contributing from incidental phenomena. By the time he became a medical professor, he had concluded that a psychiatrist's clinical skill diverged from that of other clinicians in that he or she was obligated to include the data of social adaptation. There was no question for Meyer that the psychiatrist must also master traditional clinical skills devised to collect and analyse the data of the sick body, but he advised his trainees to dispense with the disease model and the assumption that all pathological processes originated in the body. He instructed them instead to view each case as a constellation of causal factors with varying degrees of significance. In some cases, a disruption to the regulatory function of mentation indeed originated with an organic pathology such as a brain tumour or neuro-syphilis; or, it could be the result of a metabolic imbalance or external intoxicant such as alcohol or drugs. In another group of cases, however, Meyer speculated that the leading causal factors were mental, or psychobiological, in origin.

He proposed that cases commonly diagnosed as hysteria, neurasthenia and psychasthenia (widely referred to as 'functional' disorders in this period) - as well as those typically labelled dementia praecox or schizophrenia - could be categorised, more accurately, as

\footnotetext{
35 Lamb, Pathologist, op. cit. (note 12), 75-88.

${ }^{36}$ Meyer, 'Aims of a Psychiatric Clinic' (1912), op. cit. (note 29), 119.

37 Adolf Meyer, 'The Role of the Mental Factors in Psychiatry', American Journal of Insanity, 65 (1908), 44.
} 
a 'habit disorder' ${ }^{38}$ Like his contemporary Sigmund Freud had suggested for hysteria, Meyer theorised that the causal mechanism of habit disorders was conflicting instinctual, emotional and intellectual impulses. ${ }^{39}$ When mentation no longer functioned optimally as a regulator of adaptive resources, he suggested, uninhibited primitive nervous mechanisms competed with higher mental functions (such as common sense) to respond to social and symbolic stimuli. ${ }^{40}$ As a result, a person was liable to misinterpret subjective experience. If the interpretation was not corrected, the experience could become a recurring (but false) criterion for subsequent adjustments to new situations structured by common sense. ${ }^{41}$ The result was a 'pathological substitutive reaction' characterised by 'poorly planned and ill-adapted make-shifts'. For example, a 30-year-old artist from New York City who suffered from debilitating phobias was admitted to the Phipps Clinic. 'What is it you want to retreat to?' Meyer asked her, to which she replied, 'to some kind of safety, where I can at least be alone'. He explained that 'the impulse to hide is like that of a wounded animal' and the woman agreed that she was, indeed, just such a beast. Yet she was not an animal, he assured her, merely a 'bruised' person. 'A human being finds reliance in social confidence', he informed her, 'you must find a way to get out of your primitive reaction'. Despite the absence of any imminent danger, the artist could not be re-assured that her fear was unwarranted. For Meyer, this signalled a miscarriage of common sense, a biological function that was integral to social adaptation. If generalised to other stimuli and employed repeatedly, a substitute reaction could become progressively habitual and harmful, leading to a failure of social functioning and what he termed a habit disorder. Often, he referred to a substitute reaction simply as a pathological habit. ${ }^{42}$

The design and organisation of the Phipps Clinic reflected Meyer's goal to apply clinical-pathological methods to what he called psychobiological phenomena (experiencing, thinking, behaving and socialising). For him, its physical and social spaces functioned as quasi-experimental controls to study the conditions under which mental disorders developed and might be modified. By instituting a regimented hospital routine, Meyer hoped to engineer optimal conditions - as did an experimentalist in a laboratory - for detecting and better understanding abnormal psychobiological reactions. The daily routine combined therapeutic strategies long used in mental asylums (occupation, recreation and a wholesome social, or 'moral', atmosphere) and new techniques collectively called 'psychotherapy', both of which are discussed below. The

\footnotetext{
38 Adolf Meyer, 'Remarks on Habit-Disorganisations in the Essential Deteriorations, and the Relation of Deterioration to the Psychasthenic, Neurasthenic, Hysterical and Other Constitutions', Studies in Psychiatry, 1 (1912), 95-109.

${ }^{39}$ In the pre-war era, psychobiology and psychoanalysis bore more theoretical similarities than they would in later years. See Lamb, Pathologist, op. cit. (note 12), 244-5.

40 This was Meyer's pragmatic adaptation of a concept called 'dissolution' utilised by Johns Hughlings Jackson to explain causes of psychopathology as breakdowns in evolutionary hierarchy in the nervous system, in which higher functions cease to impose a normal inhibiting force on lower ones. See John Hughlings Jackson, 'Evolution and Dissolution of the Nervous System', BMJ, 1/1214 (1884), 660-3; Lamb, Pathologist, op. cit. (note 12), 68-71; Robert Richards, Darwin and the Emergence of Evolutionary Theories of Mind and Behavior (Chicago: University of Chicago Press, 1987), 280-7.

41 Adolf Meyer, 'The Relationship of Hysteria, Psychasthenia, and Dementia Praecox', Studies in Psychiatry, 1 (1912), 157.

42 Case DSE-923. All case histories cited in this paper are from Medical Records Department, Johns Hopkins Hospital, Baltimore, MD. The identities of patients are protected by substituting suitable alternatives for some biographical data.
} 
ideal of a modern psychiatric hospital, he proposed, was to create an optimal environment for artificially enforcing psychobiological balance and equanimity. ${ }^{43}$

\section{Collecting the Data of Social Adaptation}

According to Meyer, the psychiatrist gained access to the ephemeral data of social adaptation by utilising interpersonal skills and common sense as tools of clinical investigation. He contended that, as the functional result of otherwise unobservable neural mechanisms, maladaptive thinking and behaviour constituted legitimate material for scientific work. He often expressed frustration that many of his peers in science and medicine disagreed. Too often physicians surrendered their 'common sense attitude', Meyer complained, "with the conviction that this is the only admissible and scientific way'. In 1907, he deemed materialism, monism and solipsism embarrassments to scientific psychology and psychiatry. 'I should quit being a physician and a teacher', he promised members of the American Medical Association in 1915, 'if I felt compelled to doubt the possibility of my studying and knowing your minds and those of my patients well enough to draw practical conclusions'.${ }^{44}$ Critical observations of one's own mental activity and that of others, he insisted, generated objective facts admissible to the domain of science. ${ }^{45}$

The skilled psychiatrist recognised and utilised his or her own role as an object in the patient's environment. During every interview and examination, Meyer instructed, the psychiatrist ascertained 'the conduct, its inner consistency and its consistency with the situation, showing the extent of adaptation' and 'the extent of rapport with the persons and objects of the environment'. ${ }^{46}$ The deft use of social interaction and common sense facilitated the psychiatrist's assessment in this regard. 'It is usually of little importance that a patient does or says any one thing', Meyer explained, 'but that he does or says it in a definite setting, gives the act or utterance the value or adequacy or inadequacy, or normal or abnormal working' ${ }^{47}$ Clinical skill also entailed acquiring the facility for self-awareness and self-evaluation. 'Sometimes it is wise to seek the aid of a fellow physician who is more capable of meeting a particular situation', he advised readers of his 1918 manual, Outlines of Examinations. A clinical psychiatrist not only needed to regard the patient as a person in a system of social adaptation, but also himself or herself in similar terms. ${ }^{48}$

Collecting the data of social adaptation depended equally upon the psychiatrist's skill in establishing 'a safe foundation in the relation between physician and patient', in order to make accurate observations on which to base clinical judgement. ${ }^{49}$ It was critical to obtain from the patient a statement describing his or her illness and experiences. 'Make sure that the patient realises the attitude of cooperation and helpfulness', Meyer

\footnotetext{
43 Elsewhere I offer detailed analyses of Meyer's use of and patients' responses to the hospital routine in the Phipps Clinic, and of Meyerian psychotherapy, including a critical comparison of psychobiology and psychoanalysis in the pre-war period. See Lamb, Pathologist, chs 5 and 6, op. cit. (note 12).

${ }^{44}$ Adolf Meyer, 'Objective Psychology or Psychobiology with Subordination of the Medically Useless Contrast of Mental and Physical', Journal of the American Medical Association, 65 (1915), 860; Adolf Meyer, 'Misconceptions at the Bottom of Hopelessness of All Psychology by P.J. Möbius', Psychological Bulletin, 4 (1907), 171.

45 Meyer, 'Objective Psychology or Psychobiology', op. cit. (note 44), 860. See also Leys and Evans, Defining American Psychology, op. cit. (note 8), 84.

46 Adolf Meyer, Outlines of Examinations (New York: Bloomingdale Hospital Press, 1918), 20.

${ }^{47}$ Meyer, Outlines, op. cit. (note 46), 13.

48 Ibid., 11.

49 Ibid., 10.
} 
told trainees, "which alone will justify the laying bare of the material'. ${ }^{50}$ This was not straightforward with actively symptomatic psychiatric patients exhibiting delusions, hallucinations, paranoia, depression or mania. Meyer felt strongly that the creative psychiatrist could convince most patients that medical help from a doctor would prove beneficial. 'I realise the difficulty', he wrote to one of his colleagues in 1914, 'but I rather think it is best that physicians should have to exert some efforts and exercise their imagination and use their resources to the utmost' ${ }^{51}$ One way a psychiatrist accomplished this, Meyer proposed, was to develop the ability to engage with the patient's fantastic narrative conscientiously, whilst never conceding the established values of common sense. He used a provocative comparison to explain this principle in 1913:

I am as capable of listening calmly and politely to an account of a system of delusions as I am inquir[ing] into the religious and philosophical views of an oriental - with equal fairness and equal suspense of criticism and argument - and to arrive at a working agreement without any need of deception or sheer "humoring". It is possible that such an attitude becomes natural to one who looks upon any set of views as a legitimate outcome of human mentation under certain conditions, and who sees the chief task [of psychiatry] finding the conditions which led to such views. ${ }^{52}$

Using a representation of otherness that was common in European discourses at the beginning of the twentieth century, the 'oriental', Meyer advised psychiatrists to respond to bizarre manifestations of psychopathology - like Steffi's claim, below, that her thoughts were controlled by electricity - with a kind of cultural relativism appropriate to meeting a person who practised Buddhism or Islam as a result of being raised in Asia where those systems of belief were commonly revered. Indeed, as he suggests above, for the psychiatrist it should become 'natural' to view personal beliefs and experiences as products of specific environmental conditions, including delusions and pathological experiences.

The clinical psychiatrist also learned to utilise the hospital environment as a tool for collecting the data of social adaptation. 'In the hospital the patient is reduced to a common level with all the others', Meyer explained, and 'put upon a strange experimental field'. Against the backdrop of the hospital routine, he observed, peculiar reactions and behaviours were brought into relief. He instructed trainees to pay close attention to a patient's responses to encounters with fellow patients, and to visits or letters from family and friends. 'The skilled observer will see the advantage in utilising such incidents,' he explained, and benefit from 'the decided boon in being able to limit his observations on the patient and his description to the great experimental plane of ordinary hospital life'. He surmised that a patient's attempt to adjust to the relatively predictable hospital routine brought into relief abnormal patterns of social adaptation that would be far less conspicuous if observed within the everyday contexts in which they arose..$^{53}$

On the day of a patient's admission to the Phipps Clinic, a clinician conducted an initial interview with the patient and, like colleagues in other specialities, documented the individual's medical history including details about previous periods of ill health, diseases of family members and his or her medical complaints. Less common in other disciplines, the psychiatrist then undertook a lengthy 'personal history' during which he or she questioned the patient about the circumstances that preceded

${ }^{50}$ Ibid., 16.

51 Adolf Meyer to Charles P. Emerson, 2 January 1914, Folder 2, Series I/1068, AMC, op. cit. (note 4).

52 Adolf Meyer, 'The treatment of paranoic and paranoid states', in W.A. White and S.E. Jelliffe (eds), The Modern Treatment of Nervous and Mental Diseases vol. 1 (Philadelphia: Lea and Febiger, 1913), 632. Emphasis original. I have made minor grammatical changes to enhance the readability of Meyer's prose.

53 Meyer, Outlines, op. cit. (note 46), 10. 
hospitalisation, childhood experiences, schooling, family, friendships, religious views, romantic attachments, emotional responses to various aspects of life, vocation and hobbies. The psychiatrist also inquired about personal habits involving diet, tobacco, alcohol, drugs, masturbation, hygiene, sleep, leisure, birth control and sexual intercourse. ${ }^{54}$ Throughout this comprehensive interview, the skilled clinician was to simultaneously observe and document the patient's conduct and statements. Meyer utilised shorthand to describe noteworthy expressions and behaviour, and to record statements verbatim; he expected his trainees at the Phipps Clinic to do the same.

Steffi was 29 years old and lived a few blocks from the Phipps Clinic. In the outpatient dispensary, psychiatrist Esther Richards listened to Steffi explain her troubles. 'My thoughts are in electricity all the time, and people read them as I go along the streets', Steffi reported. 'In any electric streetcars or other machinery run by electricity they cast this spell on me - I find myself saying and thinking things that I do not want to say'. When Richards asked her patient to elaborate, Steffi assured her that her thoughts were 'too immodest, I won't tell you'. She used to be a good Catholic, Steffi explained, but was forced to stop going to church. 'Priests cannot say mass when I am in the room because this spell that is on me interferes with their thoughts'. Steffi had attracted attention a few months earlier when she experienced sudden attacks of pain at the underwear factory where she worked. She complained that the noisy electric machinery from another factory was casting a spell on her. Electricity compelled her to do things and she feared she might commit some dreadful act. A family member reported that she worried over trifles, sat wringing her hands, and brooded or laughed foolishly without reason. ${ }^{55}$

Once the psychiatrist elicited initial biographical details from the patient, he or she interviewed family members, friends and employers. These so-called 'informants' were asked to provide a picture of 'the make-up of the patient at his or her best' in order to help establish a comparative measure of normal. In Steffi's case history, Meyer recorded that 'the patient is described as cheerful, and for the most part easy-going'. She got along well with associates at school and in the factory, Steffi's mother reported, but she had 'always been very modest, being unwilling to undress before her sisters.' The emphases Meyer added to his clinical notes in this example stressed Steffi's usual cheerful disposition and her abnormal pre-occupation with modesty. When interviewing informants, Meyer advised the clinician to push the questions carefully in directions that elucidated the onset of illness and facts that could rule out possible diagnoses. ${ }^{56}$

The clinician then returned to the patient to conduct a comprehensive, standardised neurological examination. He or she employed well-established clinical techniques to evaluate normal functions of the nervous system: for example, reflexes, motility (symmetry of gait or ability to balance), subjective sensations (pain or dizziness), sight, touch, hearing, taste and smell. Other techniques helped to detect the presence or location of a lesion. For example, if the examiner asked the patient to stand with eyes closed and the individual repeatedly swayed (Romberg's sign), it indicated a problem of the sensory nerves, rather than the brain or mental functioning. An asymmetrical smile signalled that a patient's paralysis was due to nerve damage, rather than a psychobiological impairment. Difficulties repeating test words such as third artillery brigade or hippopotamus also pointed to the likelihood that causal factors were organic and mental factors incidental. Histological and

\footnotetext{
${ }^{54}$ Meyer, 'Mental Factors in Psychiatry', op. cit. (note 37), 41; Meyer, Outlines, op. cit. (note 46), 5.

${ }^{55}$ Case CGV-482.

${ }^{56}$ Meyer, Outlines, op. cit. (note 46), 4-11.
} 
chemical analyses clarified more parameters of the illness. Nurses collected and measured the quantity of each patient's urine, after which it was analysed chemically to test for other known disease processes. Blood and spinal fluid were drawn from every patient and tested for a Wasserman reaction, a new serological test for syphilis. Clinicians in the Department of Neurology at Johns Hopkins Hospital employed these same physical and laboratory tests to evaluate their patients. ${ }^{57}$

In the Phipps Clinic, psychiatrists also performed a comprehensive psychiatric assessment of each patient. Still in use today, Meyer lobbied to establish the 'mental status exam' as a standard clinical procedure in American psychiatry. He provided detailed and cinematic instructions for administering and interpreting its many tests in Outlines of Examinations. Like a neurological examination, its purpose was to confirm healthy modes of functioning - this time psychobiological - and identify dysfunction. It involved a lengthy series of questions and tasks that enabled the skilled clinician to gauge abilities such as abstract thought, reasoning, learning, judgment, planning, problem solving, social awareness, symbol recognition and the comprehension and expression of language. Meyer emphasised that a patient's responses to the mental status exam were relative, not absolute. When the Phipps psychiatrist Edward Kempf examined a young man who could not name the largest river in Africa, he suggested to his patient that perhaps it was the Mississippi River. 'No, the Mississippi is in the United States', the patient responded sceptically, 'you know that as well as I do'. This established for Kempf at least one marker of normal judgment. 'Perhaps it is the River Nice?' Kempf then asked, and immediately the patient remembered that the largest river in Africa was the Nile. As Kempf did here, in order to discriminate between ignorance (a normal phenomenon, relative to a patient's life experiences) and psychobiological impairment, Meyer expected psychiatrists to modify the procedure using common sense as an additional tool of evaluating results and collecting data. $^{58}$

Psychiatrists not only had to exploit, but appraise and protect their interpersonal relationships with patients. Interviews and examinations should remain fluid, and Meyer expected his clinicians to adapt themselves to the specific contexts and interpersonal dynamics of each new situation. 'Wherever the patients do not speak freely it is natural that we should first make sure that they have all they need for their comfort', he counselled. Special caution was needed when inquiring about pre-occupations, dominant ideas, delusions, hallucinations, obsessions or odd experiences. 'Take up some of the least irritating topics, such as will most likely elicit a pleasant answer and create a congenial starting point'. When a particular issue threatened to 'adulterate the account', he advised the clinician to pre-emptively employ 'ordinary human tact' to change the subject. ${ }^{59}$ Clinical skill also involved policing social contexts of interviews to obtain a complete and clear statement. Whether or not to interview a patient in the presence of family members or fellow patients, for example, depended upon the psychiatrist's judgment regarding potential gains or liabilities. ${ }^{60}$ The clinician never employed deception, ridicule, sentimentality or unnecessary argument: 'Evil results follow inevitably any false relation between patient and physician', Meyer stated emphatically. 'The patient must be treated

57 'Routine Laboratory Examinations to be Made on All Patients', circa 1914, XII/24/27, AMC, op. cit. (note 4). See also Lamb, Pathologist, op. cit. (note 12), 142-4.

58 Case LFM-844.

${ }^{59}$ Meyer, Outlines, op. cit. (note 46), 11.

${ }^{60}$ Ibid., 11. 
absolutely as a person on equal footing with the physician'. Above all, it was essential to 'get the patient's confidence as soon as possible'. ${ }^{61}$ Meyer highlighted this special aspect of psychiatry compared to other medical disciplines, encouraging trainees to collect valuable data by combining their own experience with 'imagination and memory to guide you in the examination for symptoms which others might overlook'. Both collecting and analysing the data of psychobiological reactions depended upon utilising social skills in every encounter with a patient. ${ }^{62}$

\section{Analysing the Data of Social Adaptation}

Using a revised set of clinical skills based on the instrumentalist principles of psychobiology, Meyer maintained that psychiatrists could use the clinical-pathological method to achieve what clinicians and pathologists had already accomplished for many pulmonary, infectious and neurological diseases: to identify distinctive pathological patterns particular to the development of various habit disorders. 'It will be our duty', he proclaimed to his peers in 1912, 'to define in actual cases what habits we find interwoven and with what effect' ${ }^{63}$ He held that the objective of any scientist was to discern relationships between cause and effect, stimulus and response, pathology and symptom. 'Reduction of the essential facts to terms of an experiment in nature', he decreed, 'and study of the modifiability of the experiment is the fundamental law and aim of medical science, and this holds clearly enough for the psychobiologic assets as well as for any other type of reaction' ${ }^{64}$ Nineteenth-century clinicians mobilised the idea of the clinical case as an 'experiment in nature' to emphasise that their cases had the same epistemic status as laboratory experiments, and that clinical knowledge depended upon the ability to scrutinise cases in a systematic way. Meyer deemed this an essential technique for collecting the data of social adaptation. Approaching the case as an 'experiment in nature' helped the clinician to see each patient's unique form of psychopathology as the end result of multiple causal chains, not unlike the experimentalist's results in a laboratory. ${ }^{65}$ Steffi was able to recall recent and distant events, perform calculations, recognise people she knew and correctly analyse images. Nevertheless, as Meyer explained in a clinical lecture based on this case, a segment of Steffi's mental activity was bound up in 'a realm of unrealities - a sort of parasitic growth of pathological experience'. Here, Meyer used bodily disease as metaphor in order to emphasise to his students that, like an anatomical lesion or infection, a pathological experience also had a natural development. ${ }^{66}$

He maintained that the new clinical psychiatrist must be skilled at analysing the data of social adaptation in order to formulate intermediate conclusions about the development of the patient's condition - a process he referred to as 'reconstructing' the experiment in nature. It was the German clinician Emil Kraepelin who demonstrated a legitimate method for transforming clinical observations of psychiatric patients into useable data that led

61 Ibid., 11-12.

${ }^{62}$ Meyer, Ninth Lecture: Dementia Praecox, Series XV, Box 1 (Folder: New York Period), AMC, op. cit. (note 4).

${ }^{63}$ Meyer, 'Remarks on Habit Disorganisations', op. cit. (note 38), 104.

${ }^{64}$ Meyer, 'Objective Psychology or Psychobiology', op. cit. (note 44), 861.

65 Steve Sturdy, 'Knowing Cases: Biomedicine in Edinburgh, 1887-1920', Social Studies of Science, 37/5 (2007), 659-89. For 'experiment in nature', see Engstrom, op. cit. (note 15), 101; L.S. Jacyna, Lost Words: Narratives of Language and the Brain, 1825-1926 (Princeton, NJ: Princeton University Press, 2000), 127. See also Volker Hess and J. Andrew Mendelsohn, 'Case and Series: Medical Knowledge and Paper Technology, 1600-1900', History of Science, 48 (2010), 287-315; Sturdy, 'Case Method', op. cit. (note 14).

${ }^{66}$ Op. cit. (note 55). 
to definitive results. In Germany during the 1880s and 1890s, Kraepelin compiled and compared thousands of medical histories from patients observed for months, years and decades. His quantitative analyses of these clinical data revealed two distinctive forms of insanity based on the periodicity of psychotic symptoms: episodic manic-depressive insanity versus deteriorative dementia praecox. This diagnostic distinction, established by taking a comprehensive and exhaustive medical history, was of immediate practical use to physicians as it enabled them to rule on the individual's prognosis. Kraepelin's work revolutionised attitudes about the utility of clinical work with psychiatric patients by showing that observable manifestations of their diseases - not just the brain lesions thought to cause them - could be studied scientifically and produce knowledge. ${ }^{67}$ Meyer spent the summer of 1896 apprenticing in Kraepelin's clinic and was inspired by these results. He concluded that, similarly, he might discern distinctive causal patterns in the development of mental disorders, including at the level of social functioning, by amassing and analysing large numbers of case histories. ${ }^{68}$

If the traditional case history merged observations of clinical signs and pathological lesions to create a single narrative of disease, the Meyerian case history was to represent a coherent narrative of individual maladjustment and serve as a common disciplinary object for psychiatrists. ${ }^{69}$ In contrast to Kraepelin's focus on periodicity and prognosis, Meyer explained, his aim was 'to put the emphasis on the living patient and the problems of the determination of his condition, the causes, and remedial measures'. ${ }^{70}$ In the Phipps Clinic, the case history became a dossier comprising all potentially relevant data: the patient's medical history and life experiences, results of neurological and mental status exams, the clinician's ongoing observations of both social and bodily phenomena, laboratory findings and transcripts of interviews with the patient. Its purpose was to highlight causal relationships in the development of the individual's illness and to objectify the ephemeral data of social adaptation so that 'every step is like an experiment telling us the story'. ${ }^{71}$ A conscientiously crafted case history became a 'permanent demonstration of the data'. ${ }^{72}$ Their notations, he advised, must convey the highly contextualised settings in which psychobiological reactions emerged. This was another way in which the Meyerian case history diverged from conventional practices that aimed to depict an acontextual and objective snapshot of disease. Whereas chemical reactions or physiological reflexes observed in traditional experiments remained contingent upon proximate stimuli (temporally and spatially), a psychobiological reaction involved a 'more extensive scope of potential links and interrelations' among stimuli spanning past, present and imagined experiences. ${ }^{73}$ 'To do justice to the principles of an experiment, which is the fundamental requirement of pathology, and of science in general', he explained, 'we must give each fact its true value in the chain of cause and effect'. Experience and

\footnotetext{
67 Engstrom, op. cit. (note 15), 121-46.

68 Adolf Meyer, 'A Few Trends in Modern Psychiatry', Psychological Bulletin, 1 (1904), 217-40; Adolf Meyer, 'Conditions for Psychiatric Research', Medical News, 80 (1902), 465; Meyer, 'My Experience with American Psychiatry,' unpublished manuscript, 1898, X/1/27, AMC, op. cit. (note 4). Pages 90-1.

${ }^{69}$ Guenter Risse and John Harley Warner, 'Reconstructing Clinical Activities: Patient Records in Medical History', Social History of Medicine, 5/22 (1992), 183-205.

70 Adolf Meyer, 'Organization of the medical work in the Worcester state hospital' (1912), in Collected Papers vol. 2, op. cit. (note 1), 59.

71 Meyer, 'Mental Factors in Psychiatry', op. cit. (note 37), 41.

72 Meyer, Outlines, op. cit. (note 46), 6.

${ }^{73}$ Meyer, 'Objective Psychology or Psychobiology', op. cit. (note 44), 862.
} 
social behaviour, the pragmatist Meyer repeatedly emphasised, were inseparable from their interpretive contexts. 'A reaction', he told students in 1918, 'cannot be judged without a knowledge of the stimulus'. ${ }^{74}$ He explained that the psychiatric case history must 'read like a continuous, consistent story' that depicted the patient's dynamic interaction with his or her environment. ${ }^{75}$

The patient's life experiences constituted the psychiatrist's primary material for reconstructing the experiment in nature. During daily interviews, psychiatrists asked patients to respond to questions and describe their experiences, past and present. 'Every patient has his thoroughly normal assets, and other [assets] not so well-managed', Meyer told one of his patients, '[and] they are sorted out in terms of events of the past and the way they were handled'. ${ }^{76}$ By systematising these data, the clinician aimed to identify discrepancies between the patient's adaptive resources and the demands he or she faced. Steffi recalled that a 'habit' of hers had generated heated discussion between her mother and her public school teacher. She herself could only recall that the habit was 'a nervousness that would go through her whole body'. Deducing masturbation, a few days later Meyer asked her explicitly about sexual feelings or curiosity. She vehemently denied having had any sexual thoughts, ever, and instead returned to 'vague and disguised references to the remarks about a habit at school'. In Outlines of Examination, he advised trainees that 'any suggestion that something is concealed requires special investigation'. ${ }^{77}$ Since she spoke chronically of being whipped for 'knowing too much about grown up things', he reasoned that she had been severely reproached, perhaps violently, as a child for masturbating in school. As a result of this traumatic experience, he speculated further, Steffi had misinterpreted similar sexual sensations in young adulthood as abhorrent. With mentation no longer functioning adequately to regulate conflicting impulses of fear and pleasure, his patient had substituted a primal response of hiding (in an abstract internal world), and this substitute had become progressively habitual and pathological. Just as the traditional clinician and pathologist worked collaboratively and methodically to identify organic disease processes, Meyer believed that the psychiatrist skilled in combining common sense and the methodological rigour of the clinical-pathological method could establish useful intermediate conclusions about the origins of substitute reactions and the factors that perpetuated their development. Those conclusions, he urged, ought to be applied without delay to therapeutic efforts with the patient, even as the collection and analysis of data continued throughout the hospitalisation. ${ }^{78}$

\section{Applying the Data of Social Adaptation}

Applying the data of social adaptation meant intervening in the experiment in nature, in order to modify a patient's psychobiological reactions. A psychiatrist exploited the hospital's contrived social milieu resourcefully. In cases of habit disorders, he or she focused therapeutic efforts on producing a healthy adjustment through the inculcation of more efficient adaptive habits in place of harmful ones. ${ }^{79}$ In a clinical lecture based on the case of Steffi, Meyer told students that 'where the patient is as open as this one we

\footnotetext{
${ }^{74}$ Meyer, Outlines, op. cit. (note 46), 13.

75 Ibid., 24.

76 Case SGE-889.

${ }^{77}$ Meyer, Outlines, op. cit. (note 46), 16.

${ }^{78}$ Op. cit. (note 55).

${ }^{79}$ Lamb, Pathologist, op. cit. (note 12), 167-83.
} 
may get on a footing of common interests which may crowd out much of the abnormal substitutions'. Derived from the principles of psychobiology and his concept of habit disorders, Meyer called this approach habit training. ${ }^{80}$

'Social influences,' he had declared in another lecture before his move to Johns Hopkins, 'must be brought to bear to rescue the sound instincts that are left' ${ }^{81}$ Indeed, every member of the hospital staff, according to Meyer, was obliged to interact with patients in a genuine manner, both to collect data and to serve the exercise of habit training. Twenty-sevenyear-old Lottie was one of the first patients admitted to the Phipps Clinic in 1913. Nine years earlier, while at boarding school in Europe, Lottie had suffered fits after hearing ghost stories and being teased by her classmates about her sexual ignorance. During the sea voyage home, she had accused the ship's doctor of improprieties and had become convinced that she was pregnant and disgraced. She had wept for a baby she threw into the sea, and had attempted to jump overboard four times. Once ashore she had promptly informed her parents she was married and had delivered two children (she had been gone only a few months). Throughout her hospitalisation at Phipps, Lottie experienced psychotic episodes and, alternately, long periods of stupor in which she was unresponsive to physical or social stimuli. One afternoon, however, she enjoyed an organ recital in the auditorium of the clinic. 'I wore my violet chiffon dress', she wrote her mother, 'and one of the young doctors sat beside me'. Psychiatrists observed and recorded her comment, considering it an encouraging sign of healthy participation in the social environment. ${ }^{82}$

Meyer also perceived the hospital environment as a stage for rehearsing scenarios drawn from the script of common sense that governed everyday life. Each Friday afternoon, for example, the female patients helped to plan and then attended a party in the auditorium where they served tea, played cards and danced with each other. A billiards room nearby provided a space where the male patients could socialise without female nurses or doctors. Nurses and attendants devised these special activities to recreate social spaces and interactions of everyday activities (in this period, of course, highly gendered and classed). During these exercises, theoretically, staff modelled and patients practised utilising normative social behaviours that Meyer considered essential adaptive assets.

In the contrived social milieu of the hospital, the clinical psychiatrist had to be attuned to utterances or behaviours that were significant, and be prepared to act on unexpected opportunities to advance the inquiry or treatment. Lottie had lingered in an stuporous state for many weeks. While attending one of the weekly tea parties, however, nurses noted that she 'would talk quite sensibly at intervals'. Two days later, psychiatrist Tedrow Keyser pulled up a chair in the communal women's ward to speak with another patient, placing a cushion on it as he did so. This drew Lottie's immediate attention: 'Why do you have that on there? Did you get spanked behind the barn?' Keyser slowly turned from the patient he had intended to interview and calmly asked Lottie if the cushion had reminded her of something, to which she replied, 'when my brother got spanked behind the barn'. Sensing a valuable opportunity, he immediately questioned her further. Lottie related disconnected remarks about being in the barn with her brother who afterward received a spanking from her father. When Keyser pressed her about what they were doing in the barn, 'the patient became very quiet' and then sat unresponsive for hours. Social interaction, deftly

${ }^{80}$ Op. cit. (note 55).

${ }^{81}$ Meyer, Ninth Lecture, op. cit. (note 62).

${ }^{82}$ Case EVC-283. 
combined with clinical acuity and opportunism, led Keyser to elicit significant data about possible causal factors - even from a patient as inaccessible as Lottie. ${ }^{83}$

The skilled clinician was adept not only at establishing and exploiting productive social interactions, but also at patrolling those developing around the patient. The first page of the official Nursing Manual for the Phipps Clinic in this period warned the all-female nursing staff that, while it was important to be always gracious, a nurse must remember that patients were not 'ordinary social contacts'. ${ }^{84}$ Lottie's mother repeatedly wrote to Meyer asking for his permission to visit her daughter. Taking his patient's social abilities as his gauge, he gently but consistently put her off for over six months: 'Please accept my emphatic assurance that as soon as I see that Miss Lottie is capable again of a reasonable amount of what we call rapport - in other words [the] ability to team with anyone or to have at least some mental relationship and profit from being together - I shall call on your help' ${ }^{85}$ In this explanation to Lottie's mother, he touched upon the productive nature of social relations: if Lottie herself was not able to 'profit' from the interaction, its effect was either benign or potentially detrimental. For Meyer, preserving the integrity of the therapeutic social milieu was yet another important component of clinical skill for the New Psychiatry.

Occupational therapy, employed widely as medical treatment in this period, played a central role in the regime Meyer imposed on Phipps patients. Eleanor Clark Slagle, a dominant force within this emerging profession, was the inaugural occupational therapist at the Phipps Clinic. Meyer and Slagle shared a pragmatic orientation that shaped how occupational therapy developed in the twentieth century. For them, patients did not just make baskets or play games - every activity was imbued with socialisation that could be exploited for therapeutic gain. ${ }^{86}$ 'The hold it is possible to get upon the patients as the result of these recreational and occupational methods is very remarkable', Meyer reported to the superintendent of Johns Hopkins Hospital in $1914 .{ }^{87}$ Underwriting his use of occupation was William James's instrumentalist notion that mentation merely activated instinctive drives for satisfying self-interested goals. 'Talk and feeling and thinking', he stated in 1916, 'are but a way to action'. If a person reacted to his or her thoughts and feelings with more thoughts and feelings, rather than with productive activity, it could instigate a potentially harmful process. This mental feedback loop, as it were, could lead to a 'troubling fermentation of thought and fancy' culminating in irrational phobias, delusions, debilitating anxiety or emotional extremes. ${ }^{88}$ Manual occupation and social activities interrupted rumination, Meyer theorised, directing the patient's attention away from 'attractions alluring to his morbid appetite, longings, and fancies. ${ }^{89} \mathrm{He}$ counselled one Phipps patient to 'build up a foundation of habits and interests of activity' in order to 'crowd out the feelings which have become morbidly habitual'. Playing billiards and

83 Ibid.

${ }^{84}$ Henry Phipps Psychiatric Clinic Nursing Manual, circa 1916, unpublished instruction manual consisting of sixty-eight typewritten pages bound with cloth tape and organised alphabetically by topic, XII/24/41, AMC, op. cit. (note 4). Page 2.

85 Op. cit. (note 82).

${ }^{86}$ Don M. Gordon, 'Therapeutics and Science in the History of Occupational Therapy' (PhD dissertation, University of Southern California, 2002).

${ }^{87}$ Twentieth-sixth Report of the Superintendent of the Johns Hopkins Hospital, for the Year ending January 31, 1915 (Baltimore: Johns Hopkins University Press, 1915), 21-2.

${ }^{88}$ Adolf Meyer, 'What is the safest psychology for a nurse?' (1916), in E.E. Winters (ed.), The Collected Papers of Adolf Meyer vol. 4 (Baltimore: Johns Hopkins University Press, 1952), 83-4.

${ }^{89}$ Meyer, 'Aims of a Psychiatric Clinic' (1912), op. cit. (note 30), 198. 
participating in other activities, he later told the patient's family, 'quite obviously roused some natural and helpful instincts of self-activation'. ${ }^{90}$ According to the principles of psychobiology, a psychiatrist could exploit occupational therapy and everyday activities as (artificially produced) opportunities for the patient to set productive goals and derive satisfaction from achieving them.

Finally, Meyer taught psychiatrists how to employ various psychotherapeutic techniques to continue the search for causal factors and, ideally, to modify subsequent developments in the direction of recovery. His particular brand of psychotherapy was just one of numerous forms of medical talk therapies to emerge in the United States in the decade before World War I. Meyerian psychotherapy incorporated ideas and methods developed by other theorists such as Pierre Janet, Carl Jung and Sigmund Freud, which Meyer often modified to conform to psychobiological principles. For example, he framed the psychotherapeutic encounter as a dynamic interaction between an organism (the psychiatric patient) and its environment (of which the therapist was a part). In stark contrast to Freud, then, Meyer deemed psychotherapy a collaboration between psychiatrist and patient. The assistant director of the Phipps Clinic, Macfie Campbell, described psychotherapy to one patient as 'a thorough study of subconscious adaptation' in which they would combine the patient's 'introspective insights' with his medical analysis. Meyer encouraged the same patient 'to review the facts of his life and to reconstruct the situation from which his symptoms arose'.$^{91}$ Conducting multiple interviews each day (according to a patient's capacity to collaborate), the psychiatrist utilised psychotherapy to generate insights into the origin of pathological habits, and to help the patient identify and correct misinterpreted experiences. The life story, Meyer maintained, was 'the material that you ought to be able to reconstruct into a sufficiently successful adaptation'. The skilled psychiatrist stimulated and fostered healthy social instincts. 'The physician puts something in', Meyer mused in his private notes about psychotherapy, "not content - but as a catalyzer which will enable the patient to rearrange the components of his own life, to become more and more focused and capable of performance'.$^{92}$ Requiring patients to talk endlessly about thoughts and feelings was, for Meyer, worthless without also insisting that they set and achieve concrete goals. Understanding and influencing 'actions and attitude and their adaptation', he declared, were essential clinical skills for psychiatrists in the twentieth century. ${ }^{93}$

While clinicians in other specialities evaluated the effectiveness of treatment in terms of the restoration of bodily functions, Meyer proposed that the psychiatrist did so using the measure of common sense to assess changes in individual social functioning. When Lottie's awareness of her social environment increased, for example, it indicated improvement. 'They don't give me any medicine or tonics here, so I would be just as well at home and the food would be better', she wrote to her mother after many months in the clinic. 'I am knitting you a shawl but don't know whether you will like it'. She went on to ask about the welfare of relatives and friends, and to comment on the weather in Baltimore. Her parents were delighted with her note, the most coherent utterance they had heard from her in years. A week later she wrote, 'I am up and dressed every day there is a sun parlour where we sit in most of the time and a gymnasium where we have exercises, not at all violent principally deep breathing'. Her mother forwarded the letters

\footnotetext{
${ }^{90}$ Private Correspondence, 1914, Series XV, Box B4, AMC, op. cit. (note 4).

91 Case AGH-133.

92 Meyer, Scientific Notes, n.d., XII/1/780, AMC, op. cit. (note 4).

93 Meyer, 'Mental Factors in Psychiatry', op. cit. (note 37), 586.
} 
to Meyer with her immense gratitude, describing them as 'quite wonderful'. The more connected to the social environment Lottie became, the more lucid her dispatches and the more scathing her criticisms: 'I can't stand Dr Meyer. I am sure he must be misrepresenting this place and me to you. The meals are awful. We are housed in all together and some of the patients are completely off their heads'. When Lottie had arrived at the Phipps Clinic six months earlier, she had not known where she was and had not recognised Meyer, who had treated her for many years before her admission. Now, she was acutely aware of her surroundings, which she reasonably perceived as miserable. She not only recognised Meyer but harboured definite opinions about the interrelationships between him, herself and her parents. He considered her complaints a promising sign of recovery. From Meyer's perspective, collecting, analysing and applying the data of social adaptation had enabled him and his staff to elucidate and intervene in the experiment in nature.

\section{Conclusions}

'Familiarity with the various conditions of life', Adolf Meyer assured trainees in 1918, 'and ways of succeeding and failing in psychobiological adaptation is necessary'. ${ }^{94}$ Experience and social interaction were biological functions that enabled a person to adapt successfully to a complex environment, he maintained, and they were nothing more and nothing less than natural phenomena to be subjected to scientific study. His determination to apply the logic and techniques of the clinical-pathological method to the ephemeral data of social adaptation produced a new definition of clinical skill for the progressive New Psychiatry of the twentieth century. Opportunities to advance scientific inquiry or therapeutic efforts, he taught his specialist trainees, emerged from both the patient's sick body and his or her adaptive behaviour. In addition to honing the traditional skills of the clinic, autopsy and laboratory, a psychiatrist also had to be able to employ social interaction and interpersonal relationships as investigative and therapeutic tools. As such, the Meyerian psychiatrist never allowed his or her view of the patient to crystallise. 'It has to organise and grow, to expand or shrink itself', the pragmatist Meyer explained, 'according to demands and opportunities' ${ }^{95}$

Meyer's psychobiological revision of psychiatric knowledge and skill had a significant and lasting impact on Anglo-American psychiatry in the twentieth century. Psychobiology widened clinical inquiry and psychiatric treatment to include the data of emotions, instincts, personal experience, behaviour and individual social functioning. From his powerful institutional position at Johns Hopkins, he campaigned for new affiliations between clinical psychiatry and state mental hospitals, neurology, social work, experimental psychology, sociology, education, public health and the law. Between 1913 and 1941, he trained generations of elite specialists who transported his concepts and practices to new centres of academic psychiatry in the United States, Canada and Britain. ${ }^{96}$ Many psychiatrists who trained and worked at the Phipps Clinic, such as Trigant Burrow, Jerome Frank, Alexander Leighton, Paul Lemkau and Paul Schilder, developed new investigative and therapeutic methods in psychotherapy, psychiatric epidemiology and community psychiatry - fields that today are known collectively as social psychiatry.

\footnotetext{
94 Meyer, Outlines, op. cit. (note 46), 3.

95 Meyer, Scientific Notes, n.d., XII/1/779, AMC, op. cit. (note 4).

${ }^{96}$ For example, C. Macfie Campbell, D. Ewen Cameron, Stanley Cobb, D.K. Henderson, Leo Kanner and Aubrey Lewis.
} 